\title{
Integration of Assertive Community Treatment into a Residency Curriculum: The Resident's Perspective
}

\author{
D. Walter Hiott, MD \\ Medical University of South Carolina, Charleston, South Carolina \\ Alberto B. Santos, MD \\ Medical University of South Carolina, Charleston, South Carolina
}

Follow this and additional works at: https://jdc.jefferson.edu/jeffjpsychiatry

Part of the Psychiatry Commons

Let us know how access to this document benefits you

\section{Recommended Citation}

Hiott, MD, D. Walter and Santos, MD, Alberto B. (1994) "Integration of Assertive Community Treatment into a Residency Curriculum: The Resident's Perspective," Jefferson Journal of Psychiatry. Vol. 12 : Iss. 1 , Article 5.

DOI: https://doi.org/10.29046/JJP.012.1.002

Available at: https://jdc.jefferson.edu/jeffjpsychiatry/vol12/iss1/5

This Article is brought to you for free and open access by the Jefferson Digital Commons. The Jefferson Digital Commons is a service of Thomas Jefferson University's Center for Teaching and Learning (CTL). The Commons is a showcase for Jefferson books and journals, peer-reviewed scholarly publications, unique historical collections from the University archives, and teaching tools. The Jefferson Digital Commons allows researchers and interested readers anywhere in the world to learn about and keep up to date with Jefferson scholarship. This article has been accepted for inclusion in Jefferson Journal of Psychiatry by an authorized administrator of the Jefferson Digital Commons. For more information, please contact: JeffersonDigitalCommons@jefferson.edu. 


\title{
Integration of Assertive Community Treatment Into A Residency Curriculum: The Resident's Perspective
}

\author{
D. Walter Hiott, M.D., Alberto B. Santos, M.D.
}

\begin{abstract}
Assertive Community Treatment (ACT) is a service delivery system designed to provide long-term quality care to patients with chronic mental illnesses. A brief description of these programs is presented. These programs can provide valuable training experiences for psychiatric residents. The authors report the results of their survey of residents whose training included a rotation through these services.
\end{abstract}

The care of patients with chronic psychotic disorders (schizophrenia, schizoaffective, and bipolar mood disorders) continues to be one of society's greatest challenges. These patients consume a significant portion of health care resources, as well as those of numerous other social agencies. Acute symptoms often involve the law enforcement and judicial systems while residual negative symptoms often result in significant social and occupational disability.

Prompted by a realization of the complex challenges presented by these patients and the frustration of the "revolving-door" phenomenon, the clinical staff of a State Hospital in Madison, Wisconsin conceptualized a service delivery system in which the same clinicians provided patients with a flexible, long-term, and intensive outpatient intervention $(1,2)$. In effect, the hospital staff transposed the work site of the treatment team from the inpatient setting to the community field. In the literature this approach has been variously termed Training in Community Living (3), Continuous Treatment Teams (4) or Assertive Community Treatment (5).

In the reorganization of services that characterizes Assertive Community Treatment (ACT), a multidisciplinary team provides field-based, individualized, direct treatment and rehabilitation services, continuously and indefinitely, to a limited set of patients. The ACT team's overall goals include maximizing medication compliance, residential stability, and productive activity. Over $75 \%$ of staff time is spent in the field providing direct treatment and rehabilitation (6), for example, monitoring medication effects and compliance; facilitating access to basic resources for shelter, clothing, food, and general health care; teaching and reinforcing essential skills such

From the Department of Psychiatry and Behavioral Science, Medical University of South Carolina in Charleston where Dr. Hiott is a fourth year resident and first year Fellow in Child/Adolescent Psychiatry and Dr. Santos is the Director of Psychiatry Residency Training. 
as using public transportation, budgeting, shopping, cooking, doing laundry, and house cleaning; and educating and maintaining awareness of each patient's support network. The team provides financial management and other individualized services such as the use of sign language for deaf patients.

The multidisciplinary team includes psychiatrists, nurses, social workers, activity therapists, and administrative personnel who meet daily to plan individualized care for a shared case load of 100-125 patients. The staff is available to provide direct services 24-hours a day, every day of the year. The nature and frequency of patient-staff contacts is determined by the individual's changing needs. The entire caseload is reviewed daily to anticipate patients' needs for the next 24 hours. If a patient requires close monitoring, medicine can be delivered daily as necessary. At any time, about one third of a typical caseload require intensive monitoring (1-3 times a day), one third require moderate monitoring (2-3 times a week), and one third require minimal monitoring (weekly to monthly). When a patient is hospitalized for psychiatric or other illnesses, or jailed, a team member consults with the staff of the institution daily. In most cases admission to a psychiatric hospital is limited to stabilizing patients who are at risk of harming themselves or others and who can not be managed safely in less secure settings.

The effectiveness of ACT is supported by several randomized trials comparing ACT with traditional hospital and office-based services (3,7-11). In these studies ACT demonstrated favorable outcomes regarding symptoms and level of functioning, occupational and residential status, and reduced rates of psychiatric hospitalizations. Reduced symptomatology is likely associated with the capacity of ACT teams to detect patient decompensation at an early stage and to provide timely support, education, monitoring of medication intake, and crisis intervention. ACT's effectiveness at enhancing patients' instrumental functioning is probably due to the application of individualized rehabilitative strategies in which skills are taught in the actual environment in which they are needed.

\section{INCORPORATION OF ACT INTO TRAINING CURRICULUM}

In Charleston, South Carolina there are three ACT teams, two urban teams and one rural team funded by the South Carolina Department of Mental Health. A decision was made by the Psychiatry Residency Training Program of the Medical University of South Carolina to encourage residents to pursue training in these innovative programs. In July of 1992, PGY3 residents were offered outpatient electives for 4 hours every other week in a year-long block. A total of eight positions were offered in ACTs, four in the urban program and four in the rural program. Many residents (8/14) selected public sector experiences involving ACT in urban and rural areas.

\section{EVALUATION OF TRAINING EXPERIENCES}

The eight residents involved in the ACT teams were interviewed about their experiences. In general all the residents viewed the overall experience as very 
positive. Residents appreciated the positive attitudes of staff and their ability to overcome obstacles. They enjoyed seeing patients in surroundings outside traditional clinical settings, thus experiencing patients' environments and interacting with their support systems. Residents felt they had learned a great deal about the clinical management of patients with chronic mental illness. Because less time was spent on paperwork there was a greater sense of enjoyment.

The residents found it very useful seeing a patient in his or her own environment, and they were able to gain a better understanding of the difficulties faced by this population and the reasons they have not received adequate care. They learned first hand how strongly the family and home environment can affect a person's health. The difficulty of treating this population became more apparent for the residents during this rotation, but on the other hand they were able to see how successfully intensive treatment teams work. Each team member's role in terms of benefiting the patient was perceived as very important. One resident also pointed out that he learned the significance that legislative changes have on this population.

The residents participating in the ACT rotations also learned new methods of medication management for this population. Medication compliance is an essential issue with clients seen in rural areas who have very limited access to pharmacies and transportation. The residents learned that sometimes a simplified and practical medication regimen is necessary. Conversely, residents found certain patients in urban settings require a complex medication regimen or an unusual combination of drugs which require intensive lab monitoring. Although polypharmacy is widely defined as a negative, the residents learned that in this population the use of multiple drugs is often useful or necessary.

As a rotation, residents liked the following about the ACT experience: 1) working in a program that has well-defined treatment goals, is efficient, and takes a team approach to outpatient treatment; 2) being able to participate in all aspects of treatment and seeing improvement over time in the patient's life; 3) getting to spend more time with the patient and thus getting to know the patient better including support system and family; 4) having an opportunity to work with the families of the patients; and 5) being exposed to a new patient population.

Residents saw the following as negatives: 1) the extensive amount of time spent traveling to see patients in the rural ACT team and the limited numbers of patient who could be seen in an afternoon as a result; and 2) the rising numbers of patients for whom care is provided without concurrent increase in number of staff because of limited funding.

All the residents felt that this rotation would be valuable for all psychiatry residents as part of their curriculum. Their comments regarding this included, "This experience (has been one of the) two most valuable experiences I've had in my residency. It brings home the real impact of psychiatric illness and the difficulties of treating patients in low income rural areas. The approach to treatment planning must be much more pragmatic"; "This has been an invaluable experience that should be part of any resident's training who is interested in public mental health or the treatment of patients with chronic mental illness"; "This would help others to 
appreciate how different your perspective is when seeing patients in their homes"; "A similar experience of making home visits should be required of all residents in order to gain insight"; "This program moves psychiatry into the community and promotes wiser spending of health care money"; "Without this, a resident would miss a specific patient population that seems easily overlooked and is also underserved; it's the population that used to live in the state hospital"; "I can now better understand how someone can be treated outside of the hospital when seriously ill and know that we have something to offer them."

Many of the residents also related particular cases that they felt were representative of what the program had to offer:

1) "A gentleman who had been homebound for seven years locked himself in his room and never left. His family slid food to him under the door. His house had no running water and no bathroom. He lived with ten other people in a four-bedroom house. As a result of management by the program, the patient now leaves his room, ventures outside, and interacts with his family. He also receives disability and has a water and sewage hook-up. Social supports have been lined up for the entire family. Educating the family has also been vital."

2) "There is a man who lives alone on one of the local islands who has been diagnosed with schizophrenia and alcohol abuse. He is able to work at a shrimping dock a few days per week. He lives in a low income district and his house is in poor shape. In the past, he has frequently stopped taking his medication and then becomes intrusive and paranoid. He has required multiple hospitalizations. Visiting him, the team noticed that he had placed a wire in the middle of the dirt driveway to his home. Since he has done this in the past, this served as a clue that he was getting paranoid, which was not obvious by talking to him alone. By noting this change in his environment, we were able to detect a problem much earlier, change his medication regimen, and prevent the usual pattern of exacerbation after non-compliance from occurring."

3) "On a home visit, I saw a new patient who was psychotic. A nurse who was with me knew that this was not her baseline level of functioning. I was able to give her medication on the spot and make other appropriate changes in her treatment plan so that further deterioration and probably hospitalization was avoided. I feel that without this intervention, she would not have sought help and would have further decompensated, resulting in a forced visit to the emergency room or mental health center."

4) "I remember seeing a certain patient on several occasions as an intern who was severely ill with bipolar affective disorder. He spent more time in the hospital than out. He could become very paranoid and violent. Since his involvement with this program, however, I have seen a tremendous turnaround in this man's life. He is now a volunteer and is able to handle his own medications and see the importance of it-none of which he was able to do before. It has been very rewarding to see this."

5) "I have seen a couple who were both diagnosed with schizophrenia. They live in a mobile home without running water or electricity. I have learned that treating them is not just using neuroleptics but involves meeting other personal needs as well. 
I feel that I care more about them, and I find that I am less concerned about spending time on medication adjustments and side effects. For example, they have cats, dogs, pigs, and goats, and I feel that our visits have helped the animals as well. After seeing how they interact with them, I was able to teach them more appropriate ways to care for their pets. We have also been working on getting better housing, water, and electricity; spending money more wisely; and teaching them basic health and sanitation. I will remember them because I was involved in all areas of their treatment."

6) "I think of a woman who had been hospitalized for depression with psychotic features. In the hospital, she was noted to have syphilis but refused (due to her state of mind) a spinal tap to rule out neurosyphilis. She was discharged and scheduled to have the spinal tap done as an outpatient, which was done. The fluid tested positive, but because the patient didn't return for follow-up, this went unnoticed. In a traditional setting, this information would have more likely fallen between the cracks. Fortunately, when the team obtained her records and intensively reviewed her chart, this was picked up. She was readmitted to the hospital for treatment with IV antibiotics. Interestingly, she has not been symptomatic since."

In conclusion, seven out of the eight residents said that this experience would make them more likely to pursue a career in public or community psychiatry on either a part-time or full-time basis.

\section{DISCUSSION}

An orientation toward community-based services such as those provided by ACT programs is timely, given the significant national trend away from centralized institutional care, the growing importance of cost containment and the evolution of patient treatment in the least restrictive setting. Increasingly, public sector patients are being cared for through cost-effective, community-based programs such as ACT. Exposure to service delivery models other than hospital and office-based aftercare provides psychiatric residents a practical lesson in medical economics in that these programs demonstrate cost containment without jeopardizing the quality of care.

It is important to find the means to offer trainees a broader clinical exposure to patients, which includes a longitudinal perspective on psychopathology and an appreciation of patients' adaptive functioning during non-acute phases of illness. Such efforts will result in better trained professionals who can effectively advocate for patients as they negotiate community, legal, and social systems. Psychiatrists with this training will be better able to project the potential benefits and limitations of rehabilitation efforts, appreciate the fluid nature of psychiatric symptoms, discriminate baseline from relapse characteristics, and competently assess functional deficits.

The organizational structure and procedures of ACT teams and hospital-based psychiatric teams have many similarities including daily rounds, a multidisciplinary treatment team, and an organizational hierarchy. These similarities make them "user friendly" for residency training. The principal difference, however, is that ACTs function as "continuous treatment teams" caring for patients while in or out of 
hospitals, rather than the traditional inpatient "episodic care teams" providing direct services only during hospital-based care. The absence of a time limit allows for long-term and continuous assessment and clinical care rather than brief episodic care or crisis intervention. The continuous long-term approach also encourages formation of a stronger therapeutic alliance. Early identification of symptom relapse is facilitated by staff as well as patients and family who can alert staff, so that medications can be adjusted or other interventions planned in a timely fashion.

ACT is gradually gaining acceptance as a viable service system with over 300 programs in 25 states currently operating. It is the most intensively studied out-ofhospital service delivery system for seriously mentally ill patients with nine controlled studies and several others underway. It is inherently appealing because it provides for the flexible integration of treatments and services for a population with complex needs. Its inherent appeal is likely to make it one of the most popular training experiences in a residency training curriculum. When public mental health services are viewed as rewarding and enjoyable, more psychiatry residents will be willing to enter the sector.

\section{REFERENCES}

1. Marx AJ, Test MA, Stein LI: Exterohospital Management of Severe Mental Illness: Feasibility and Effects of Social Functioning. Arch Gen Psychiatry 1973; 29:505

2. Stein LI, Test MA: Training in community living-one year evaluation. Am J Psychiatry 1976; 133:917-918

3. Stein LI, Test MA: Alternatives to mental health hospital treatment, I. Conceptual model, treatment program and clinical evaluation. Arch Gen Psychiatry 1980; 37:392-397

4. Torrey EF: Continuous treatment teams in the care of the chronic mentally ill. Hosp Community Psychiatry 1986; 37:1243-1247

5. Taube CA, Morlock L, Burns BJ, Santos AB: New directions in research on assertive community treatment. Hosp Community Psychiatry 1990; 41:642-647

6. Brekke JS, Test MA: An empirical analysis of services delivered in a model community support program. Psychosocial Rehabilitation Journal 1980; 10:51-61

7. Mulder R: Final evaluation of the Harbinger program as a demonstration project. Unpublished manuscript, August 1982

8. Hoult J, Reynolds J: Schizophrenia: A comparative trial of community oriented and hospital oriented psychiatric care. Acta Psychiatr Scand 1984; 69:359-372

9. Bond GR, Miller LD, Krumwied RD, Ward RS: Assertive case management in three MHCs: a controlled study. Hosp Community Psychiatry 1988; 39:411-418

10. Jerrell JM, Hu T: Cost-effectiveness of intensive clinical and case management compared with an existing system of care. Inquiry 1989; 26:224-234

11. Bond GR, Witheridge TF, Dincin J, Wasmer D, Webb J, DeGraaf-Kaser R: Assertive community treatment for frequent users of psychiatric hospitals in a large city: a controlled study. Am J Community Psychol 1990; 18:865-872 